\title{
Useful Daily Behaviour to RemoveAsymptomatic Bacteriuria in an Eight Years Age Girl with Spina Bifida Occulta
}

\author{
Taniguchi K ${ }^{1}$, Nakashima T², Ichiyama Y3 ${ }^{3}$ Yamamoto H $^{4}$, Uemichi K
}

\begin{abstract}
Asymptomatic bacteriuria is occasionally found in healthy children. However, the fact that spina bifida occulta can be hidden in asymptomatic bacteriuria is not well known. We report an eight years age girl with asymptomatic bacteriuria. Spina bifida occulta was revealed by radiological examinations. Simple daily behaviour, consisting of keeping the genitals clean, rehydrating regularly and not prolonging urination, was useful for removing asymptomatic bacteriuria in spina bifida occulta.
\end{abstract}

Key words: Asymptomatic bacteriuria, spina bifida occulta, simple daily behaviour

\section{Introduction}

symptomatic bacteriuria is a common finding in healthy adult women and individuals with diabetes or abnormalities of the genitourinary tract ${ }^{1,2}$, and is occasionally found in healthy children examined in screening urinalyses at schools ${ }^{3,4,5}$. However, the fact that spina bifida occulta can be hidden in asymptomatic bacteriuria is not well known. We report a case of spina bifida occulta hidden in asymptomatic bacteriuria in a healthy eight years age girl. Simple daily behaviour, consisting of keeping the genitals clean, rehydrating regularly and not prolonging urination, proved to be useful for removing asymptomatic bacteriuria in spina bifida occulta.

\section{The Case}

All procedures followed were in accordance with the ethical standards of the responsible committee (Tara Town Hospital, Japan) and with the Helsinki Declaration of 1975, as revised in 2013. Written informed consent was received from the family members of the patient for the publication of this report.

An eight years age girl with an unremarkable medical history was picked up in a screening urinalysis at school. Leukocyturia, implying existence of bacteria, was detected. She had no symptoms and a physical examination found no abnormalities. We performed some laboratory examinations. A microscopic examination showed bacteriuria containing Gram-negative bacteria. A culture examination revealed Escherichia coli at $1 \times 10^{8} / \mathrm{ml}$ in the urine. Blood tests, including leukocyte count and measurement of C-reactive protein, detected no abnormalities. Although bacteriuria disappeared after oral
${ }^{1} \mathrm{Dr}$. Kazuto Taniguchi, MD, PhD, ${ }^{2} \mathrm{Dr}$. Takema Nakashima, MD, ${ }^{3} \mathrm{Dr}$. Yasunobu Ichiyama, MD. ${ }^{4}$ Dr. Hirokazu Yamamoto, MD, ${ }^{5}$ Dr. Kazuyasu Uemichi, MD. All from Tara Town Hospital, 1520-12 Tara, Saga 849-1602, Japan.

\author{
Address for correspondence \\ Dr. Kazuto Taniguchi \\ Mailing address: Tara Town Hospital, 1520-12 \\ Tara, Saga 849-1602, Japan. \\ Tel: +81-954-67-0016 \\ Fax: +81-954-67-0068 \\ Email: tgene1@po.hagakure.ne.jp
}

\section{How to cite}

Taniguchi K, Nakashima T, Ichiyama Y, Yamamoto H, Uemichi K. Useful Daily Behaviour to Remove Asymptomatic Bacteriuria in an Eight Years Age Girl with Spina Bifida Occulta. J Nepal Paediatr Soc 2018;38(1):56-58.

doi:http://dx.doi.org/10.3126/jnps.v38i1.19904

This work is licensed under a Creative Commons Attribution 3.0 License.

\section{(c) (i)}


medication with cefdinir for seven days, it reappeared a month later without symptoms (Table 1).

We performed radiological examinations to investigate the cause of the asymptomatic bacteriuria. Enhanced computed tomography revealed dissociation of the first sacrum confirming a diagnosis of spina bifida occulta (Figure 1), but no inflammatory lesion or renal abnormality was found. Magnetic resonance imaging also illustrated dissociation of the first sacrum (Figure 1), but did not show either a lipoma or a spinal cord abnormality, as well-known complications of spina bifida. Intravenous pyelography detected no abnormality in the urinary tract (data not shown).

We suggested efforts toward appropriate daily behaviour to remove the bacteriuria instead of treatment with antibiotic agents. The patient has made concrete efforts to keep the genitals clean, rehydrate regularly and not prolong urination. Since commencing this simple daily behaviour, bacteriuria has disappeared for more than eight months (Table 1).

\section{Discussion}

We observed two important clinical issues in our patient: spina bifida occulta can hide in asymptomatic bacteriuria of healthy children, and appropriate daily behaviour to remove asymptomatic bacteriuria in spina bifida occulta is useful.

First, spina bifida occulta should be considered as a cause of asymptomatic bacteriuria. Spina bifida occulta can impair bladder function, which is intricately controlled by sacral nerves, and the resulting bladder dysfunction can be a potential risk for urinary tract infection and renal parenchyma failure ${ }^{6}$. Although the bacteriuria in the present patient persisted without bladder dysfunction symptoms such as dysuria, we should consider medical care to prevent urinary tract infection and renal parenchyma failure.

Second, efforts toward appropriate daily behaviour to remove asymptomatic bacteriuria were successful. Treatment for asymptomatic bacteriuria with antibiotic agents is not recommended, because mismanagement of asymptomatic bacteriuria can not only potentially trigger antimicrobial resistance but also result in unnecessary side effects ${ }^{7,8}$. Nicolle ${ }^{9}$ described that antimicrobial treatment for asymptomatic bacteriuria did not decrease the frequency of symptomatic infection. Our procedure had no risk of injuring the patient's health unlike antibiotic agents, and the effects were longlasting.

Persistence with constant daily behaviour is sometimes difficult. Some situations, such as complicated behaviour components or requirement for a particular device, may induce poor adherence. If patients are toddlers, family members should manage their behaviour. In the present case, the required behaviour, involving keeping the genitals clean, rehydrating regularly and not prolonging urination, was so simple that the patient could easily support the behaviour herself with sufficient understanding. Our procedure was not a burden for the patient either physically or mentally. We occasionally provided a theoretical explanation of our idea and purpose to help keep her motivated. As the relationship of mutual trust between her and us grew stronger, it led to increasing confidence in her continuing efforts.

Table 1: Results of urinalyses before and after cefdinir

\begin{tabular}{ccccc}
\hline & Before & Immediately after & Month later & \multicolumn{2}{c}{ Daily behaviour } \\
\hline Leukocytes & $(+)$ & $(-)$ & $(+)$ & $(-)$ \\
Gram-negative bacteria & $(+)$ & $(-)$ & $(+)$ & $(-)$ \\
\hline
\end{tabular}
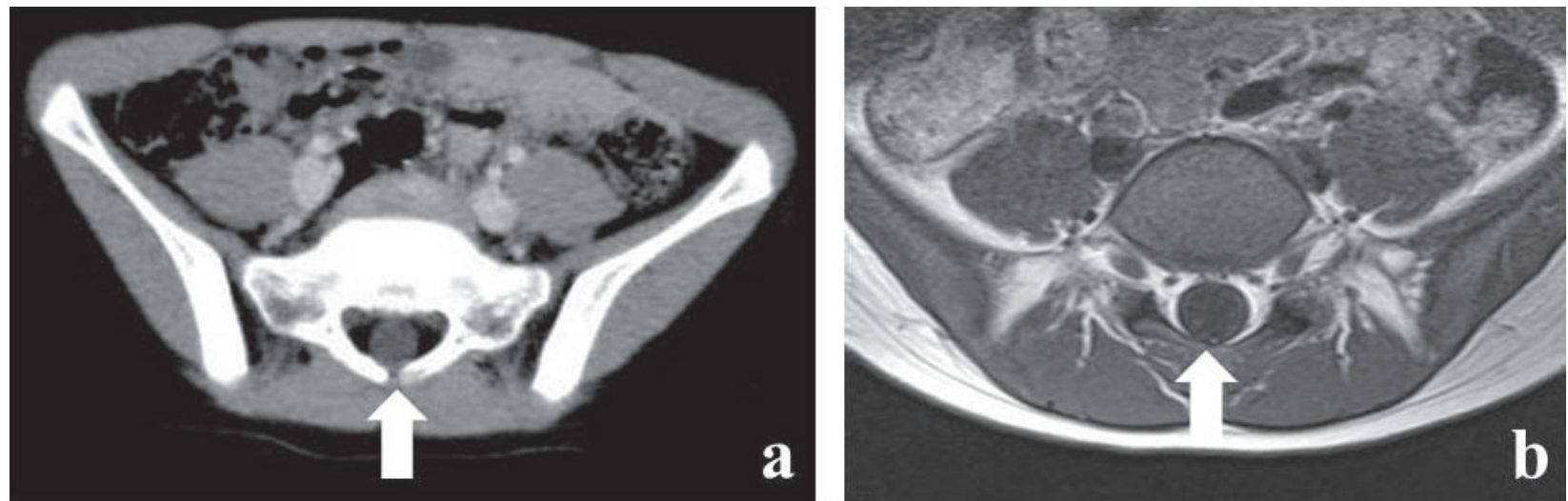

Fig 1: The diagnosis of spina bifida occulta. Enhanced computed tomography (a) and magnetic resonance imaging (b) revealed dissociation of the first sacrum (arrows) without other abnormalities. 


\section{Conclusion}

Spina bifida occulta can hide in asymptomatic bacteriuria, and simple daily behaviour is useful for removing asymptomatic bacteriuria in spina bifida occulta. We must be aware that spina bifida occulta can be hidden in asymptomatic bacteriuria in healthy

\section{References}

1. Nicolle LE.Asymptomatic bacteriuria: when to screen and when to treat. Infect Dis Clin North Am2003;17(2):367-394. DOI: https://doi.org/10.1016/ S0891-5520(03)00008-4.

2. Nicolle LE, Bradley S, Colgan R, Rice JC, et al. Infectious Diseases Society of America guideline for the diagnosis and treatment of asymptomatic bacteriuria in adults. Clin Infect Dis 2005;40(5):64354. DOI: https://doi.org/10.1086/427507.

3. Caksen H, Arslan S, Abuhandan M, Celik A, Bozkurt $\mathrm{H}$, Odabaş $\mathrm{D}$. Asymptomatic bacteriuria in infants in eastern Turkey. Acta Paediatr Taiwan 2001;42(6): 338-39.

4. Yayli G, Yaman H, Demirdal T. Asymptomatic bacteriuria rates in schoolchildren: results from a rural city in Turkey. J Trop Pediatr 2003;49(4):228-30. DOI: https://doi.org/10.1093/tropej/49.4.228. children, and that some spina bifida occulta cases may remain unrecognized. Further reports should be accumulated to determine whether spina bifida occulta is much more frequently present that expected and whether simple daily behaviour can contribute to removing asymptomatic bacteriuria in spina bifida occulta.

5. Mohammed A, Abdelfattah M, Ibraheem A, Younes A.A study of asymptomatic bacteriuria in Egyptian schoolgoing children. Afr Health Sci 2016;16(1):69-74. DOI: 10.4314/ahs.v16i1.9.

6. Johnston LB, Borzyskowski M. Bladder dysfunction and neurological disability at presentation in closed spina bifida. Arch Dis Child 1998;79(1):33-8. DOI: http://dx.doi.org/10.1136/adc.79.1.33.

7. Eyer MM, Läng M, Aujesky D. Overtreatment of asymptomatic bacteriuria: a qualitative study. J Hosp Infect 2016;93(3):297-303. DOI: 10.1016/j. jhin.2016.04.007.

8. Flokas ME, Andreatos N, Alevizakos M, Kalbasi A, Onur P, Mylonakis E.Inappropriate management of asymptomatic patients with positive urine cultures: a systemic review and metaanalysis. Open Forum Infect Dis 2017;4(4):ofx207. DOI: 10.1093/ofid/ofx207.

9. Nicolle LE. The paradigm shift to non-treatment of asymptomatic bacteriuria. Pathogens 2016;5(2):E38. DOI: 10.3390/pathogens5020038. 